Bull. Mater. Sci., Vol. 22, No. 5, August 1999, pp. 851-861. Indian Academy of Sciences.

\title{
Integrated computational chemistry system for catalysts design
}

\author{
S SALAI CHEETTU AMMAL, SEIICHI TAKAMI, MOMOJI KUBO and \\ AKIRA MIYAMOTO* \\ Department of Materials Chemistry, Graduate School of Engineering, Tohoku University, Aoba-yama 07, \\ Sendai 980-8579, Japan
}

\begin{abstract}
The understanding of valuable catalytic and adsorptive properties of heterogeneous catalysts at atomic and electronic levels is essential for the design of novel catalysts. Computer simulation studies can significantly contribute to provide a rational interpretation of the observed experimental results and suggest modification of new catalysts. Our recent work on the application of integrated computer simulation methods to investigate the structure and catalytic propertles of solid surfaces including zeolites, transition metals and their oxides have been reviewed in this paper. We have emphasized the effectivity and applicability of integrated computer simulation system to solve the problems in a variety of targets of industrial and academic importance.
\end{abstract}

Keywords. Integrated computational chemistry; density functional theory; molecular dynamics; catalyst design.

\section{Introduction}

The application of computational chemistry techniques not only provides the basis for understanding the structural and electronic features of the catalysts but also enables us to readily probe the effects of altering transition metals, and manipulating the nature of the active site or changing the active-particle-size ensemble. This will be the first step towards the long-term goal of catalyst design. The next step would be the rigorous description and energetics predictions for each elementary reaction step of the entire catalytic cycle from first principles theoretical methods. This has been so far an unattainable goal owing to limitations of computer (CPU) requirements as well as limitations of accuracy of the available computational methods. But with the advent of more powerful computing facilities and the development of various computational methodologies, achieving this goal has become more or less a possibility. The integrated application of quantum chemistry (QC), molecular dynamics (MD), Monte Carlo (MC) simulations and computer graphics $(\mathrm{CG})$ can provide a powerful and reliable tool for probing into ideas and predicting properties in the area of catalyst design. In this paper, we will review our recent applications of integrated computer simulation system to the design of solid catalysts and the investigation of catalytic reactions on solid surfaces.

Zeolites, in particular, are interesting systems for computational studies since their structures, in most

*Author for correspondence instances, are defined and known, in contrast to the amorphous catalysts. A fundamental understanding of the structure, dynamics and energetics of such solid catalysts and their modification according to the reaction conditions are important to develop efficient catalysts. The structure and dynamics of the framework atoms, extra framework atoms, and guest molecules have been widely studied (Demontis et al 1987; Titiloye et al 1991; Santikary et al 1992; Nicholas et al 1993). Recently, QC techniques have been applied to investigate the adsorption configuration of various molecules on the zeolite catalysts and the mechanisms of various reactions using cluster models (Sauer 1989; Beran 1990). We have used a combination of $\mathrm{QC}, \mathrm{MD}$, and $\mathrm{MC}$ techniques to study the different aspects of zeolites, such as structure-property correlation, adsorption phenomenon, and ion-exchange behaviour. We have applied combinatorial-computationalchemistry approach as well to reproduce the performance of known catalysts and thereby predict new catalysts with improved performances.

The characterization of electronic structure and molecular bonding in transition metals and their oxides is an attractive and a challenging area. Study of the electronic properties of metals and their oxides pose some difficulties which are mainly due to the presence of many unpaired electrons that result in a large number of electronic states. However, in the last few years, density functional theory (DFT) has emerged as a promising tool for the investigation of transition metal systems, in particular for the oxides (Broclawik and Salahub 1994; Broclawik 1995). Therefore, we have applied DFT methods to investigate the electronic structure and 
adsorption properties of precious metals and their oxides. We have also studied the adsorption of NO molecule on rhodium and palladium clusters, methane activation on $\mathrm{Rh}$ and $\mathrm{Pd}$ clusters and their oxides, and the important interactions in the de- $\mathrm{NO}_{x}$ process.

Considering the dynamic nature of catalysis and the significance of temperature and pressure in a catalytic process, the molecular dynamics study at different conditions which are close to the practical ones is necessary to describe and understand the catalytic process atomistically. Hence, we have applied the MD technique to study the dynamic features of $\mathrm{TiO}_{2}$ surfaces (Yin et al 1997). To elucidate the nature of catalysis, investigation at the electronic level is essential. Theoretical studies reported so far on the catalytic processes are mainly based on the cluster approach. However, the selection of appropriate model clusters for their surface systems is still a problem. In such cases, periodic density functional methods are therefore more relevant for reliable predictions. We have used periodic DFT calculations to investigate the structural and electronic properties of both $\mathrm{V}_{2} \mathrm{O}_{5}$ bulk and (001) surface (Yin et al 1998), which has shown excellent consistence with the experimental data and thus has laid a foundation for application of the periodic DFT for adsorption systems. Based on these results, further investigations on hydrogen adsorption, water adsorption, ammonia and nitric oxide adsorption on $\mathrm{V}_{2} \mathrm{O}_{5}$ surface were carried out (Yin et al 1999a-d). In addition, we also have studied the mechanism of selective catalytic reduction of nitric oxide by ammonia on the $\mathrm{V}_{2} \mathrm{O}_{5}$ surface.

\section{Computational methodology}

The computational methods adopted in our present studies can be divided into three main categories: (i) molecular dynamics, (ii) quantum chemical calculations using density functional theory, and (iii) computer graphics.

\subsection{Molecular dynamics}

MD calculations were carried out with the MXDORTO program developed by Kawamura (1989). While the Verlet (1967) algorithm was used for the calculation of atomic motions, the Ewald (1921) method was applied for the calculation of electrostatic interactions. Temperature and pressure were controlled by means of scaling of atomic velocities and unit cell parameters under threedimensional periodic boundary conditions. The two-body, central force interatomic potential, as shown in (1), was used for all the calculations. In (1), the first, second and third terms refer to Coulomb, exchange repulsion, and Morse interactions, respectively,

$$
\begin{aligned}
U\left(r_{i j}\right) & =Z_{i} Z_{j} e^{2} / r_{i j}+f_{0}\left(b_{i}+b_{j}\right) \exp \left[\left(a_{i}+a_{j}-r_{i j}\right) /\left(b_{i}+b_{j}\right)\right] \\
& +D_{i j}\left\{\exp \left[-2 \beta_{i j}\left(r_{i j}-r_{i j}^{*}\right)\right]-2 \exp \left[-\beta_{i j}\left(r_{i j}-r_{i j}^{*}\right)\right]\right\}
\end{aligned}
$$

where $Z_{i}$ is the atomic charge, $e$ the elementary electric charge, $r_{i j}$ the interatomic distance and $f_{0}$ a constant. The parameters $a$ and $b$ in (1) represent the size and stiffness in the exchange repulsion interaction, while $D_{i j}, r_{i j}^{*}$ and $\beta_{i j}$ represent bond energy, equilibrium bond distance and stiffness in the Morse function, respectively.

\subsection{Quantum chemical calculations using density functional theory}

DFT was applied to investigate the electronic properties, surface structure, adsorption phenomena, reaction mechanism on the surfaces etc. The calculations for cluster models were carried out using the self-consistent KohnSham formalism (Kohn and Sham 1965), as implemented in the DMol program of MSI (von Barth and Hedin 1972). The geometry optimizations were carried out using a double numerical plus polarization (DNP) basis set (Delley 1990). Janak-Moruzzi-Williams (JMW) functional (Moruzzi et al 1978) or Vosko-Wilk-Nussair (VWN) functional (Vosko et al 1980) was used for local density approximation. We used Becke (1988) and Lee-YangParr (BLYP) functionals (Lee et al 1988) for the nonlocal gradient corrections to obtain the accurate energy values.

The periodic density functional calculations were carried out using the DSolid program of MSI. In this program, the one-electron Schrödinger equations are solved only at $k=0$ wavevector point ( $\Gamma$ point) of the Brillouin zone. We used VWN local-type functional for the geometry optimizations, whereas the interaction energies were computed using the BLYP non-local-type functional. The DNP basis set was employed.

We also employed CASTEP program (Teter et al 1989) of MSI for the periodic density functional calculations. CASTEP uses a conjugated gradient technique in a direct minimization of the Kohn-Sham energy functional. Basis sets used here are plane-wave functions. Using this approach, the lattice constants are optimized to obtain stable structures. Exchange and correlation effects were included within the Ceperley-Alder local density approximation (Perdew and Zunger 1981) as well as in the generalized gradient approximation.

\subsection{Static visualization}

The static visualization by computer graphics (CG) of molecular configurations as snapshots during $\mathrm{MD}$ simulations as well as the plots of optimized molecular geometries from DFT calculations were made with the 
INSIGHTII code of MSI on a Silicon Graphics IRISIndigo2 engineering workstation. The dynamic visualization of the MD simulations was made with MOMOVIE and RYUGA (Miura et al 1995) programs developed in our laboratory on OMRON-LUNA-88K and HP9000 Model $715 / 33$ workstations, respectively.

\section{Results and discussion}

We applied integrated computer simulation technique to a variety of targets of industrial and academic importance, in particular to the: (i) structure and property correlation in zeolites, including adsorption and reactions, (ii) electronic structure and adsorption properties of precious metals and their oxides, and (iii) geometries, adsorption properties and reactions of transition metal oxide surfaces.

\subsection{Structure and property correlation in zeolites}

We used MD, CG and quantum chemical methods to investigate the structure and catalytic properties of the zeolites.

3.1a Zeolite structures: $\mathrm{MD}$ and CG methods were applied to investigate the anisotropic lattice expansion and to estimate the probable sites for substitution of silicon by titanium in MFI lattice (Oumi et al 1995). It was demonstrated that the MD method, using a simple two-body interatomic potential, is effective in reproducing the framework structure. The lattice expansion as a function of the concentration of $\mathrm{Ti}$ in the titanosilicate with the MFI structure was calculated and the results were consistent with the experimental data. The favourable site for $\mathrm{Ti}$ substitution was proposed by comparing the anisotropic expansions of lattice parameters with X-ray diffraction studies. The MD and CG methods appear to be promising for explaining intricate processes, such as isomorphous substitution and the resulting anisotropic lattice expansion.

The structure and dynamic behaviour of gallium and cerium cations in cation-exchanged ZSM-5 framework were calculated using the $M D$ and $C G$ techniques (Miyamoto et al 1994) and their relevance in the catalytic removal of nitric oxide discussed. The dynamic freedom of the extraframework oxygen attached to gallium and cerium, and the low coordination of these cations to framework oxygen atoms in ZSM-5, compared to the situation in metal oxides, could be the reason for the observed high catalytic activity of the gallium and ceriumexchanged ZSM-5.

Additional studies on the structure and electronic properties of metallosilicates were carried out using the MD and quantum chemical (DFT) methods (Oumi et al 1997). In the first step, MD calculations were used to study the local relaxation in the T12 site of the ZSM-5 structure, where $\mathrm{Si}$ was substituted by different metals such as $\mathrm{Ti}^{4+}, \mathrm{Al}^{3+}, \mathrm{Ga}^{3+}$, and $\mathrm{Fe}^{3+}$. Figure 1 shows the $\mathrm{CG}$ picture of H-ZSM-5, where one of the T12 sites is substituted by an $\mathrm{Al}$ atom. The cluster models were then generated from the structure obtained from MD calculations, and $\mathrm{QC}$ calculations were used on those models to study their electronic properties. The results revealed that to assess the acidic properties of metallosilicates, the net charge on the $\mathrm{MO}_{4}$ unit $(\mathrm{M}=\mathrm{Ti}, \mathrm{Al}, \mathrm{Ga}$, and $\mathrm{Fe}$ ), and the molecular electrostatic potential values would be good parameters, as confirmed by their correlations with the reported experimental acidity.

3.1b Activity of $\mathrm{Ga}-\mathrm{ZSM}-5$ in the de-NO $\mathrm{O}_{x}$ process: Recently, much attention has been given to $\mathrm{Ga}$ - and Inexchanged ZSM-5, which have been found to promote the reduction of NO by methane (Kikuchi and Yogo 1994). Methane has been generally considered as a relatively inactive agent and it is only recently that the TPD investigations have indicated the dissociative adsorption of methane on Ga-ZSM-5 (Tabata et al 1994). Our earlier MD calculations on the local structure of mono- and multivalent Ga-exchanged ZSM-5 (Miyamoto and Kubo 1993; Miyamoto et al 1994), suggested that the low coordination around the $\mathrm{Ga}$ centre resulted in the high performance of $\mathrm{Ga}-\mathrm{ZSM}-5$ for the de-NO $\mathrm{N}_{x}$ reaction. Our preliminary quantum chemical investigations on the electronic structure of Ga-ZSM-5 (Vetrivel et al 1995) also showed that the extraframework oxygen was surrounded by a much larger region of strong negative electrostatic potential than any other framework oxygen. Thus, based on these results we extended our investigations on the Ga-ZSM-5 catalyst to identify its role in the adsorption and activation of methane molecule (Himei et al 1995).

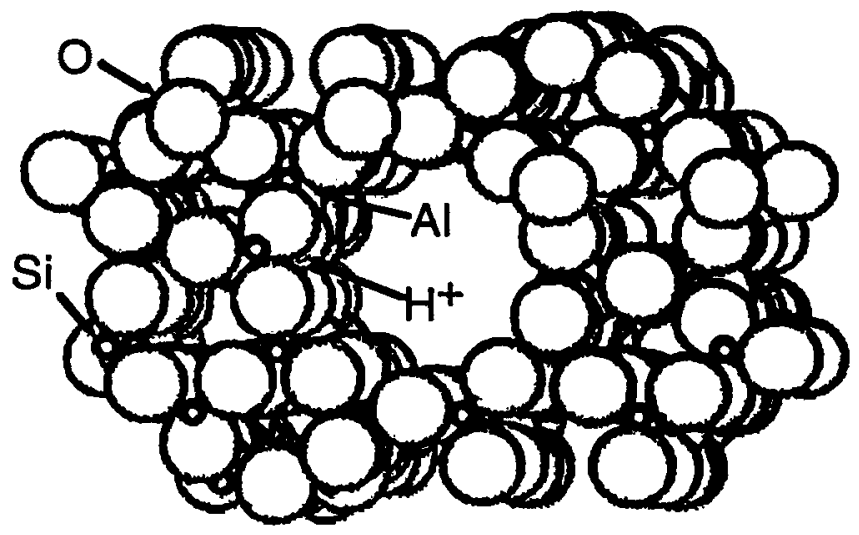

Figure 1. The CG picture of the H-ZSM-5 lattice at $300 \mathrm{~K}$ after 30000-time steps of each $Z \times 10^{-15} \mathrm{~s}$ in the MD simulation. One of the T12 sites is substituted by an $\mathrm{Al}$ atom in the unit cell. 
Quantum chemical density functional calculations were used for the system of a MD-derived model cluster of zeolite (figure 2) and methane or water molecules. In the initial step, the methane molecule underwent weak physical adsorption on a $\mathrm{Ga}$ site at a distance of $2.9 \AA$ between the $\mathrm{Ga}$ and carbon atoms with an adsorption energy of $-4.90 \mathrm{kcal} / \mathrm{mol}$. In the next step, the dissociative adsorption of methane showed that the dissociated complex with $\mathrm{CH}_{3}$ attached to $\mathrm{Ga}$ and $\mathrm{H}$ bonded to extraframework oxygen appeared to be favourable and led to energetic stabilization of $-63.0 \mathrm{kcal} / \mathrm{mol}$. No stable physisorbed state of water was observed, but the dissociated form of $\mathrm{H}_{2} \mathrm{O}$ appeared to be strongly bonded at the $\mathrm{Ga}$ site. The comparison of both processes therefore allows for the discussion on the influence of water poisoning on the activation process. The adsorption energy of the dissociated water molecule at the optimized geometry is $-77.5 \mathrm{kcal} / \mathrm{mol}$ which is substantially larger than that of a physisorbed or dissociated methane molecule. This may result in prevention of methane activation. Moreover methane adsorption on a $\mathrm{Ga}$ site, already poisoned by water, seems too weak to allow for any further transformation.

We further extended our study to describe the reaction pathway of methane dissociation on the Ga-exchanged zeolitic centre, using the DFT method (Broclawik et al 1995). Structures of the various adsorption modes of methane on $\mathrm{Ga}$ active site in the methane dissociation reaction were investigated: (i) physisorbed methane, (ii) $\mathrm{C}-\mathrm{H}$ dissociation product, and (iii) transition state (figure 3). The geometries of the optimized structures and energies are given in table 1 . In the physisorbed state, the methane molecule acquires a slightly positive charge, whereas in the transition state, some flow of charge towards already formed methyl group was noticed. The activation barrier was estimated to be $28.7 \mathrm{kcal} / \mathrm{mol}$. The transition state for the hydrogen transfer between the carbon and oxygen was additionally stabilized not only by increased interaction of the gallium cation with the methyl carbon but also by the interaction of the polarized extraframework oxygen and the dissociative hydrogen. Thus our model reveals that both constituents of the postulated

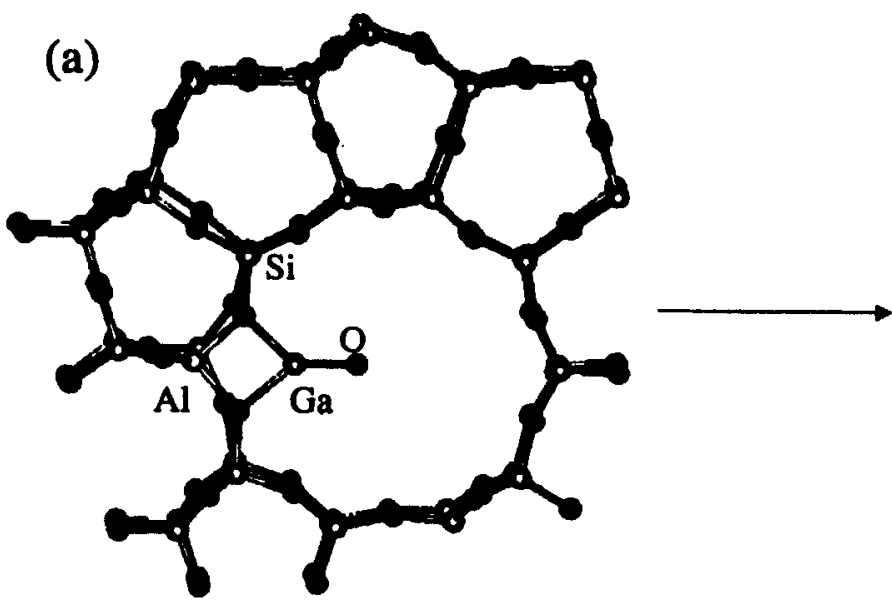

(b)

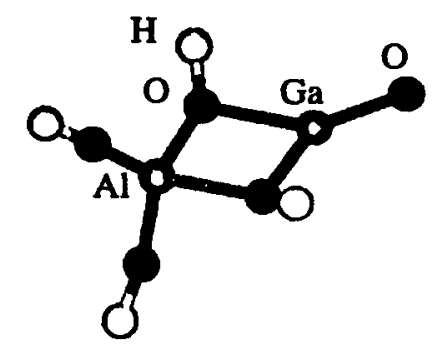

Figure 2. a. MD-simulated ZSM-5 framework with the exchanged gallium site, b. cluster model used for the DFT calculations.

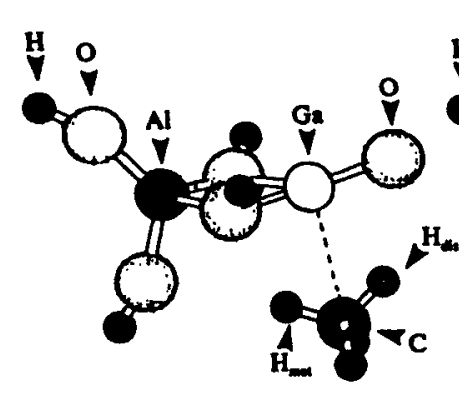

(a)

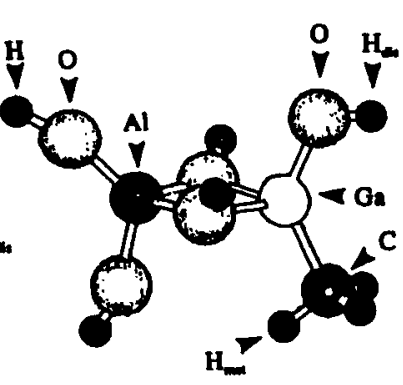

(b)

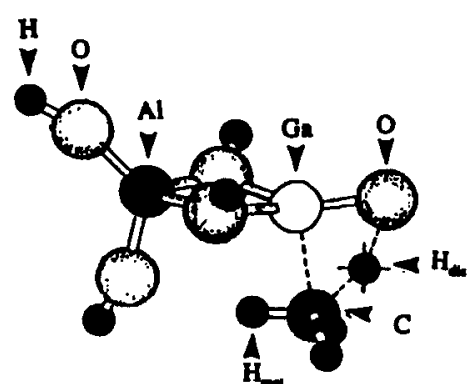

(c)

Figure 3. Structures of the various adsorption modes of methane on Ga active site in the methane dissociation reaction: $\mathbf{a}$. physisorbed methane, b. dissociated methane, $\mathbf{c}$. transition state. 
$\mathrm{GaO}^{+}$active unit should play important roles in the $\mathrm{C}-\mathrm{H}$ bond scission.

In another study, we used MD, CG and QC methods to study the adsorption of $\mathrm{NO}_{x}$ molecules on Ga-ZSM-5 (Yamadaya et al 1997). For the $\mathrm{NO}_{x}$ molecules, no energy barrier was observed before chemisorption. The adsorption energy for $\mathrm{NO}$ and $\mathrm{NO}_{2}$ were computed to be -18.4 and $-10.3 \mathrm{kcal} / \mathrm{mol}$, respectively. The examination of the adsorption states of the $\mathrm{NO}$ and $\mathrm{NO}_{2}$ molecules pointed out the differences of the adsorption properties of these two molecules. In keeping with the experimental data, we also predicted that the $\mathrm{NO}_{2}$ molecule would get more activated on the Ga site than the NO molecule. The spin distribution analysis showed that $\mathrm{NO}_{2}$ is significantly activated after adsorption. It was also observed that the $\mathrm{Ga}$ atom is stabilized and tetrahedrally coordinated after the adsorption process.

3.1c Combinatorial computational approach for the de-NO $\mathrm{N}_{x}$ catalyst design: Combinatorial experimental methods contribute significantly to the area of catalysis. However, because of their high cost, limited access, toxicity, etc, combinatorial computational methods are more effective to design new catalysts with high performance. Thus the combinatorial computational approach is complementary to the experiments in exploring new frontiers of research in the area of catalysis.

MD calculations were carried out to determine the framework structures of various ion-exchanged ZSM-5, where the exchanged cations were $\mathrm{Ga}, \mathrm{In}, \mathrm{Cu}, \mathrm{Ag}$, and $\mathrm{Co}$. Our calculations showed that whereas $\mathrm{Ga}, \mathrm{Cu}$ and $\mathrm{Co}$ prefer doubly-coordinated states, In and $\mathrm{Ag}$ will prefer both doubly- and triply-coordinated states (Kanougi et al 1997). Further, the DFT calculations to study the adsorption states of $\mathrm{NO}_{2}$ on these ion-exchanged ZSM-5 (table 2) showed that In could adsorb $\mathrm{NO}_{2}$ with relatively large adsorption energy compared to $\mathrm{Ga}$. The adsorption results in the formation of a nitrato complex $\left(\mathrm{NO}_{3}^{-}\right)$. While adsorption modes on $\mathrm{Cu}$ and $\mathrm{Ag}$ can be either $\eta^{1}-\mathrm{N}$ or $\eta^{2}-$ $O$, O, on Co only $\eta^{1}-N$ was possible. In these ZSM-5, the adsorption results in the formation of a nitrito complex $\left(\mathrm{NO}_{2}\right)^{-}$. Moreover, among all these metals, Co would perhaps exhibit the largest adsorption energy.

Further, we applied combinatorial computational approach to study the poisoning effect of $\mathrm{H}_{2} \mathrm{O}$ and $\mathrm{SO}_{2}$ for the adsorption of $\mathrm{NO}$ and $\mathrm{NO}_{2}$ molecules on ionexchanged ZSM-5. A lot of metals such as $\mathrm{Fe}^{2+}, \mathrm{Co}^{2+}$, $\mathrm{Cu}^{2+}, \mathrm{Pt}^{2+}, \mathrm{Pd}^{2+}, \mathrm{Al}^{3+}, \mathrm{Ga}^{3+}, \mathrm{In}^{3+}, \mathrm{Ir}^{3+}$, and $\mathrm{Tl}^{3+}$ were selected as the exchanged cations in ZSM-5. The resistance towards water poisoning for the adsorption of NO molecule on the ion-exchanged ZSM-5 was evaluated by the difference between the adsorption energies of NO and $\mathrm{H}_{2} \mathrm{O}$ molecules. Likewise, the resistance towards $\mathrm{H}_{2} \mathrm{O}$ poisoning for the adsorption of $\mathrm{NO}_{2}$ molecule as well as the resistance towards $\mathrm{SO}_{2}$ poisoning for the adsorption of $\mathrm{NO}$ and $\mathrm{NO}_{2}$ molecules were evaluated and plotted (figure 4). DFT method was used to calculate the adsorption energies and the results have predicted that $\mathrm{Pd}^{2+}$ shows

Table 1. Formation energies $\Delta E$ (LDA, in Ry) and selected geometrical parameters for reactants, substrate. transition state, and dissociation product.

\begin{tabular}{lccccccc}
\hline & $\begin{array}{c}\Delta E \\
(\mathrm{Ry})\end{array}$ & $\begin{array}{c}R_{\mathrm{Ga}-\mathrm{C}} \\
(\AA)\end{array}$ & $\begin{array}{c}R_{\mathrm{C}-\mathrm{H} \text { met }} \\
(\AA)\end{array}$ & $\begin{array}{c}R_{\mathrm{C}-\text { Hdis }} \\
(\AA)\end{array}$ & $\begin{array}{c}R_{\mathrm{Q}-\mathrm{H}} \\
(\AA)\end{array}$ & $\begin{array}{c}R_{\mathrm{Ga-O}} \\
(\AA)\end{array}$ & $\begin{array}{c}\alpha_{\mathrm{CCaO}} \\
(\mathrm{deg})\end{array}$ \\
\hline Cluster and molecule & - & - & 1.10 & 1.10 & - & 1.67 & $\overline{97}$ \\
Physisorbed methane & -0.00687 & 2.77 & 1.11 & 1.12 & 2.46 & 1.67 & $\mathbf{9 7}$ \\
TS & +0.01378 & 2.19 & 1.10 & 1.35 & 1.47 & 1.72 & 88 \\
Dissociated methane & -0.08866 & 1.93 & 1.10 & 3.54 & 0.98 & 1.80 & 133 \\
\hline
\end{tabular}

Table 2. $\mathrm{NO}_{2}$ adsorption on ZSM-5: adsorption energies $E_{\text {ads }}$ in $\mathrm{kcal} / \mathrm{mol}$, total charge on $\mathrm{NO}_{2}$ $(Q)$, and metal- $\mathrm{NO}_{2}$ bond lengths.

\begin{tabular}{|c|c|c|c|c|c|}
\hline ZSM-5 & $E_{\text {ads }}(\mathrm{LDA})$ & $E_{\mathrm{uds}}(\mathrm{BLYP})$ & $Q$ & M-ONO $(\AA)$ & $\mathrm{M}-\mathrm{NO}_{2}(\AA)$ \\
\hline $\begin{array}{l}\mathrm{Ga} \\
\text { In } \\
\mathrm{Cu}\left(\eta^{\prime}-\mathrm{N}\right)^{\mathrm{a}}\end{array}$ & $\begin{array}{l}-36 \cdot 4 \\
-59 \cdot 8 \\
-46 \cdot 3\end{array}$ & $\begin{array}{l}-10.4 \\
-33.5 \\
-30.7\end{array}$ & $\begin{array}{l}-0.09 \\
-0.10 \\
-0.19\end{array}$ & $\begin{array}{l}1.98 \\
2 \cdot 26 \\
-\end{array}$ & $\frac{-}{1.87}$ \\
\hline $\mathrm{Cu}\left(\eta^{2}-0.0\right)^{\mathrm{b}}$ & -48.7 & $-34 \cdot 2$ & -0.35 & $\begin{array}{l}1.96 \\
1.97\end{array}$ & - \\
\hline$A g\left(\eta^{\prime}-N\right)^{a}$ & $-24 \cdot 6$ & -8.6 & -0.21 & - & $2 \cdot 13$ \\
\hline $\mathrm{Ag}\left(\eta^{2}-0,0\right)^{b}$ & -23.7 & -9.8 & -0.36 & $\begin{array}{l}2.21 \\
2.24\end{array}$ & - \\
\hline Co & -69.5 & $-37 \cdot 3$ & -0.10 & - & 1.71 \\
\hline
\end{tabular}

aMonodentate coordination where $\mathrm{NO}_{2}$ interacts with the metal through $\mathrm{N}$ atom.

${ }^{b}$ Bidentate interaction where the metal interacts equally with the 2 oxygen atoms of $\mathrm{NO}_{2}$. 
resistance to $\mathrm{H}_{2} \mathrm{O}$ and $\mathrm{SO}_{2}$ poisoning. This result is consistent with the experimental observations. Based on this knowledge, we predicted the performance of some new elements and our calculations showed that $\mathrm{Ir}^{3+}$ could show good resistance towards $\mathrm{H}_{2} \mathrm{O}$ as well as $\mathrm{SO}_{2}$ poisoning. In conclusion, the performance of known catalysts has been reproduced and new catalysts with higher performances have been predicted.

\subsection{Electronic structure and adsorption properties of precious metals and their oxides}

Transition metals, especially precious metals such as $\mathrm{Rh}$, $\mathrm{Pd}$ and Pt play essential role in automobile exhaust catalyst (Kummer 1986; Shelef and Graham 1994) as the active ingredients of the so-called three way catalysts (TWC). Its crucial component was $\mathrm{Rh}$, and it was well accepted that the key factor in the efficiency of Rh over $\mathrm{Pd}$ or $\mathrm{Pt}$ was due to the better performance of the $\mathrm{Rh}$ in the $\mathrm{NO}_{x}$ reduction process. In order to understand the basic reason for the efficiency of $\mathrm{Rh}$ over $\mathrm{Pd}$ or $\mathrm{Pt}$, as well as the electronic role of the precious metals in the cata- lytic processes, we carried out DFT calculations on the interactions of the $\mathrm{NO}_{x}$ molecules with $\mathrm{Rh}$ and $\mathrm{Pd}$ atoms (Stirling et al 1996). From the cluster calculations, a stronger metal-nitrogen bond in RhNO molecule than in the PdNO system was predicted (table 3 ). This stronger bond also suggested a larger $\pi$ contribution between Rh and $\mathrm{N}$ atoms. Such interaction would result in weakening the NO bond since it increases the population on the NO $2 \pi^{*}$ antibonding orbital. Next we carried out the periodic density functional calculations on $\mathrm{MgO}(100)$ supported $\mathrm{Rh}$ nitrosyl complex. From our calculations we concluded that possibly the support significantly influenced the Rh-N bonding and that the NO group itself was also likely to be affected by the support surface.

In another study, we carried out spin-unrestricted DFT calculations for the adsorption of $\mathrm{NO}$ on $\mathrm{M}_{2}$ and $\mathrm{MO}$ ( $M=R h, P d$ ) clusters (Endou et al 1997) and showed that NO could be adsorbed in a bridge position on $\mathbf{M}_{2}$ and in a bent configuration on MO. The adsorption energy was predicted to be larger for $\mathbf{R h}$. The overall charge transfer was observed to be the back donation of electrons to the adsorbate which could lead to the weakening of the NO

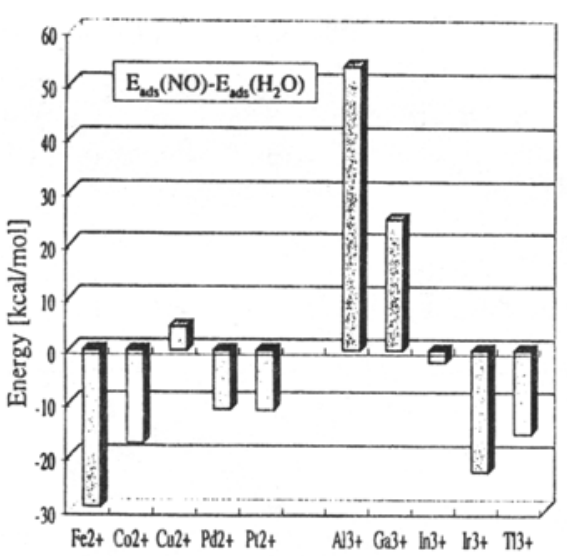

(a)

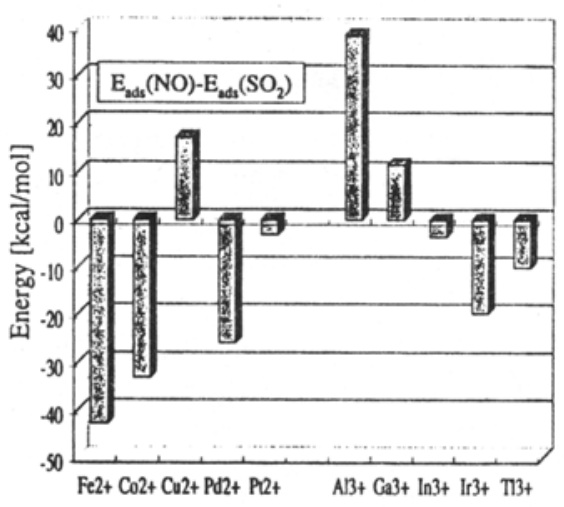

(c)

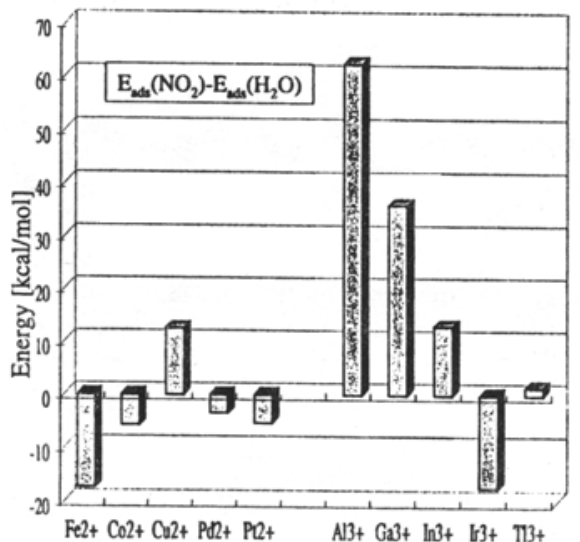

(b)

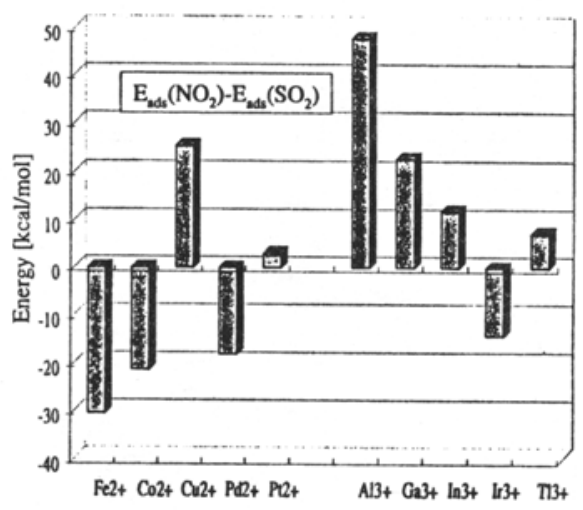

(d)

Figure 4. Poisoning effect of $\mathrm{H}_{2} \mathrm{O}$ and $\mathrm{SO}_{2}$ in the adsorption of $\mathrm{NO}$ (a. and c.) and $\mathrm{NO}_{2}$ (b. and d.) molecules on various ion-exchanged ZSM-5. 
Table 3. Calculated properties of RhNO and PdNO.

\begin{tabular}{lccccc}
\hline & \multicolumn{2}{c}{ Rh-NO } & & \multicolumn{2}{c}{ Pd-NO } \\
\cline { 2 - 3 } \cline { 6 - 6 } Parameters & VWN & BLYP & & VWN & BLYP \\
\hline$D_{\text {No }}(\AA)$ & 1.190 & 1.218 & & 1.187 & 1.209 \\
$D_{M-N}(\AA)$ & 1.743 & 1.799 & & 1.888 & 1.972 \\
$\alpha_{M-N-O}(\mathrm{deg})$ & 134.1 & 130.1 & & 127.5 & 130.7 \\
$\mu(D)$ & 2.897 & 3.031 & & 1.742 & 2.027 \\
$E_{M-N}\left(\mathrm{kcal} / \mathrm{mol}^{*}\right)$ & 118.3 & -93.0 & & -47.8 & -30.5 \\
$V_{1}$ NO str. $\left(\mathrm{cm}^{-1}\right)$ & 1716 & 1512 & & 1702 & 1547 \\
$V_{2} M-N$ str. $\left(\mathrm{cm}^{-1}\right)$ & 707 & 623 & & 545 & 454 \\
$V_{3} M-N-O$ bend. $\left(\mathrm{cm}^{-1}\right)$ & 174 & 153 & & 218 & 200 \\
\hline
\end{tabular}

* M denotes $\mathrm{Rh}$ or $\mathrm{Pd}$

bond. The adsorption energy was predicted to decrease when the metal was oxidized to MO.

Further, the electronic structure of PdO and the interaction of methane molecule with $M_{2}$ and $M O(M=R h$, Pd) were calculated by DFT methodology (Broclawik et al 1996, 1997). The two triplets, ${ }^{3} \mathrm{II}$ and ${ }^{3} \Sigma^{-}$in PdO, possibly lie very close in energy, with the indication of ${ }^{3} \Pi$ as the ground state of the oxide. The adsorption studies showed that the strongest non-dissociative adsorption of methane occurred in a bridging position on $\mathrm{Pd}_{2}$ (table 4) accompanied by very strong activation of a $\mathrm{C}-\mathrm{H}$ bond and a negligible energy barrier for the bond scission. The adsorptions on other systems were weaker and had a large energy barrier. This could be ascribed to the absence of repulsive $5 \mathrm{~s}$ electrons in the case of palladium dimer. However, a strongest stabilization of the dissociated hydrogen was found to occur on PdO. These results were useful in explaining the experimental data which indicated that a supported palladium catalyst, showing subsequently metallic and oxidized phases, is a very efficient medium for methane combustion.

\subsection{Geometries, adsorption properties and reactions of transition metal oxide surfaces}

Heterogeneous catalysis of transition metal oxides is based mainly on the surface structure of the catalyst. Apparently, characterizing the physical and chemical properties of a surface is one of the most important parts towards understanding the nature of the catalytic process.

3.3a Structure of $\mathrm{TiO}_{2}$ surfaces: $\mathrm{We}$ used $\mathrm{MD}$ calculations to investigate the surface relaxations of the three $\mathrm{TiO}_{2}$ phases, namely, rutile, anatase and brookite (Yin et al 1997). We first performed MD simulation on rutile (110) and (001) surfaces (figure 5). The results showed that the (001) surface exhibits larger relaxations than the (110) surface. Our calculated energies at $300 \mathrm{~K}$ showed that the (110) surface is more stable by
Table 4. Relative energies (in $\mathrm{kcal} / \mathrm{mol}$ ) of various adsorption states of methane on Pd and $\mathrm{Rh}$ systems calculated at LDA level.

\begin{tabular}{lccccc}
\hline & Co-linear & On-lop & Bridge & TS & Dis \\
\hline PdO & -20 & -9 & -6 & +5 & -53 \\
$\mathrm{Pd}_{2}$ & -17 & -24 & -26 & -23 & -37 \\
$\mathrm{RhO}$ & -19 & -6 & -4 & +10 & -33 \\
$\mathrm{Rh}_{2}$ & -11 & -7 & -6 & & -25 \\
$\mathrm{Pd}$ & & -4 & & +16 & +9 \\
$\mathrm{Rh}$ & & +6 & & +14 & -5 \\
\hline
\end{tabular}

$2.6 \mathrm{kcal} / \mathrm{mol}$. The analysis of atomic coordinations showed that the higher atomic coordinations of $\mathrm{Ti}$ and $\mathrm{O}$ atoms on the (110) surface lead to higher thermal stability compared to the (001) surface. MD calculations on anatase (110) and (001) surfaces predicted that the (001) surface will be more stable than the (110) surface by $7.2 \mathrm{kcal} / \mathrm{mol}$. Likewise, the calculations on brookite (010) and (001) surfaces showed that in case of unrelaxed surfaces, the (010) surface will be more stable by $5.3 \mathrm{kcal} / \mathrm{mol}$. The reason for the stability was also interpreted from the atomic coordinations of the $\mathrm{Ti}$ atoms on the surface.

3.3b Periodic DFT study on $\mathrm{V}_{2} \mathrm{O}_{5}$ bulk and (001) surface: The catalytic properties of $\mathrm{V}_{2} \mathrm{O}_{5}$-based catalysts depend strongly on their ability to provide lattice oxygens as a reactant in oxidation of hydrocarbons. There are three kinds of oxygen atoms: (i) $\mathrm{O}_{1}$ singly coordinated, which is the vanadyl oxygen; (ii) $\mathrm{O}_{2}$ doubly coordinated; and (iii) $\mathrm{O}_{3}$ triply coordinated. Different experimental studies proposed different oxygens as the active site. In this section, we have presented the recent periodic DFT calculations of $\mathrm{V}_{2} \mathrm{O}_{5}$ bulk and (001) surface (Yin et al 1998). The geometries optimized at GGA level (figure 6) were in good agreement with the experimental data. Charges on oxygen atoms decreased in the order: -0.68 $\left(\mathrm{O}_{3}\right)>-0.56\left(\mathrm{O}_{2}\right)>-0.37\left(\mathrm{O}_{1}\right)$. Mulliken overlap populations suggested that the $\mathrm{V}-\mathrm{O}_{1}$ bond is stronger than the $\mathrm{V}-\mathrm{O}_{2}$ or $\mathrm{V}-\mathrm{O}_{3}$ bond. Therefore, $\mathrm{V}-\mathrm{O}_{1}$ is more covalent 
than the other possible $\mathrm{V}-\mathrm{O}$ bonds. For the (001) surface, the structures and electronic properties were very close to that of the bulk. The projected density of states (PDOS) showed that $\mathrm{O}_{1}$-occupied levels were closer to Fermi level than those of $\mathrm{O}_{2}$ and $\mathrm{O}_{3}$. This suggests that acidic species such as proton will perhaps interact with $\mathrm{O}_{1}$ rather than $\mathrm{O}_{2}$ or $\mathrm{O}_{3}$. Therefore, the basicity of the surface should decrease in the order, $\mathrm{O}_{1}>\mathrm{O}_{2}>\mathrm{O}_{3}$.

$3.3 \mathrm{c}$ Adsorption of hydrogen on $\mathrm{V}_{2} \mathrm{O}_{5}(010)$ surface: Periodic DFT calculations were used to investigate the hydrogen adsorption on $\mathrm{V}_{2} \mathrm{O}_{5}(010)$ surface ( $\mathrm{Y}$ in et al 1999a). The effect of local environment of an adsorption site as well as lattice relaxation were investigated by adopting the following systematic optimization methods: (i) optimization of only the $z$-coordinates of the $\mathrm{H}$-atom
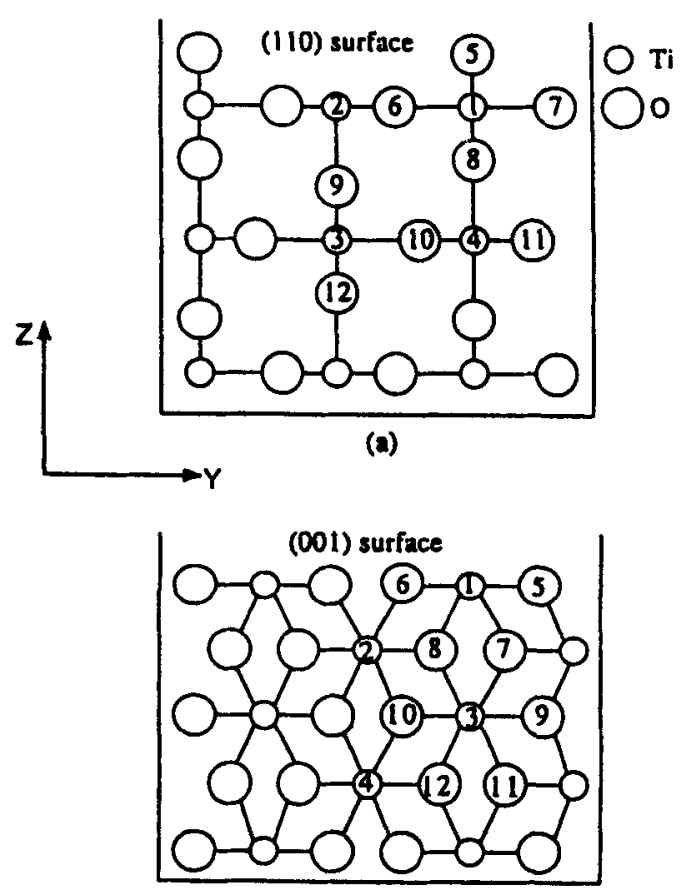

(b)

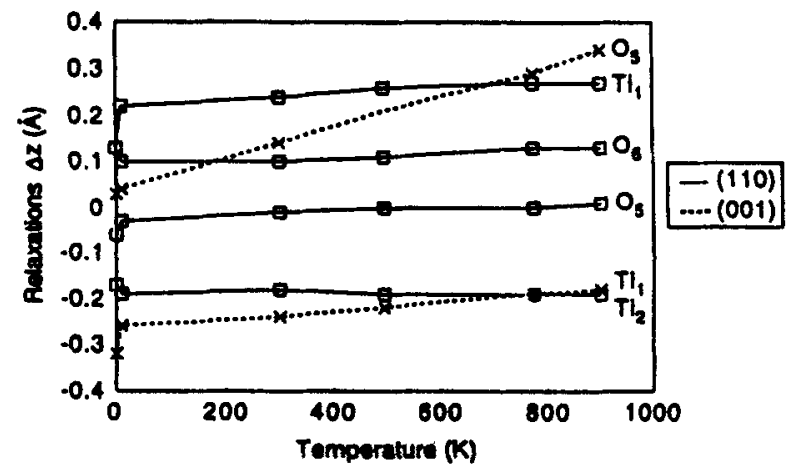

(c)

Figure 5. Rutile surfaces of $\mathrm{TiO}_{2}$. a. (110) surface, b. (001) surface, $c$. evolution of the relaxation with temperature. and its corresponding adsorption site, (ii) optimization of all the three coordinates of the $\mathrm{O}-\mathrm{H}$ group, and (iii) full optimization of all the constituent atoms of the adsorbatesubstrate system. The geometries obtained from step (iii) have been represented in figure 7. Our calculations showed that the vanadyl oxygen should act as the most active site towards hydrogen adsorption. While lattice relaxation contributes in all the cases to reactivity of the surface oxygens significantly, local environment of adsorption site will affect both geometry as well as the reactivity of the adsorption system only for tricoordinated oxygen. The calculated vibrational frequencies of these three types of hydroxyl species showed (i) the difference among these three types of hydroxyl species, (ii) and their correlation to bond strength, as well as support their reactivity. Comparison of the desorption ability of the $\mathrm{OH}$ species from the surface showed that removal of the $\mathrm{O}_{1} \mathrm{H}$ species, formed by $\mathrm{H}$ adsorption at vanadyl oxygen, is energetically preferable. It was also found that the processes of hydrogen adsorption, $\mathrm{OH}$ desorption and $\mathrm{O}$ vacancy formation can be correlated.

3.3d Adsorption of $\mathrm{H}_{2} \mathrm{O}$ on $\mathrm{V}_{2} \mathrm{O}_{5}(010)$ surface: The interaction of water with metal oxide surfaces has significant influence on their catalytic behaviour. Here we investigated the molecular and dissociative adsorption of water molecule on the $\mathrm{V}_{2} \mathrm{O}_{5}(010)$ surface by means of periodic boundary models and DFT approach (Yin $e t$ al $1999 \mathrm{~b}$ ). Our results showed that molecular adsorption of $\mathrm{H}_{2} \mathrm{O}$ takes place at the exposed penta-coordinated vanadium and the three structurally different surface oxygens that support the experimental identifications. For molecular adsorption at the exposed vanadium site, coordination interaction and hydrogen bonding were predicted to play the key role. Regarding the molecular adsorption at the surface oxygen, the model predicted that the hydrogen bonding plays a crucial role, and the

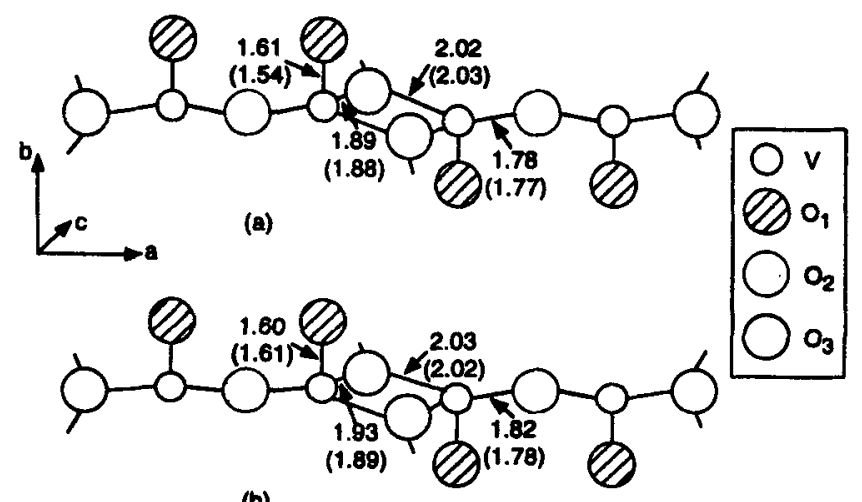

(b)

Figure 6. The optimized $\mathrm{V}-\mathrm{O}$ bond lengths in $\mathrm{a} . \mathrm{V}_{2} \mathrm{O}_{5}$ bulk (the corresponding experimental values are shown in the brackets), and $b$. $\mathrm{V}_{2} \mathrm{O}_{5}(001)$ surface (the corresponding optimized bulk values are in the brackets). 
electron donation from the surface oxygen sites to the water molecule would be the dominant contributor.

On the other hand, dissociation of water molecule would hardly be possible on the stoichiometric (010) surface, mainly due to the pronounced Coulombic repulsion between the lattice oxygens around the exposed vanadium centre and the oxygen of the hydroxyl species. For both molecular and dissociative adsorption, the prediction was that the vanadyl oxygen would play the most important role.

3.3e Adsorption of $\mathrm{NH}_{3}$ on $\mathrm{V}_{2} \mathrm{O}_{5}(010)$ surface: The mechanism of selective catalytic reduction (SCR) of NO by $\mathrm{NH}_{3}$ on $\mathrm{V}_{2} \mathrm{O}_{5}$ catalyst is mainly discussed on the basis of the adsorption states of $\mathrm{NO}$ and $\mathrm{NH}_{3}$ on the catalyst surface, which are directly related to the pathway of the reaction. In order to understand the mechanism of the SCR reactions, molecular adsorption of $\mathrm{NH}_{3}$ on the Brönsted as well as the Lewis sites of $\mathrm{V}_{2} \mathrm{O}_{5}$ surface were investigated (Yin et al 1999c). The results pointed out that $\mathbf{N H}_{3}$ adsorption would take place on both sites, and the adsorption on the Brönsted sites would be more favoured energetically. At first, when ammonia molecule approaches to the three kinds of Brönsted acid sites on $\mathrm{V}_{2} \mathrm{O}_{5}(010)$ surface, it was observed that $\mathrm{NH}_{3}$ is strongly adsorbed on these sites, and subsequently $\mathrm{NH}_{4}^{+}$ions are formed (figure 8). The adsorption at the $\mathrm{O}_{1} \mathrm{H}$ group was found to be energetically more favourable. As well as it was found that the newly formed $\mathrm{NH}_{4}^{+}$ion strongly interacts with the vanadyl oxygen adjacent to the $\mathrm{V}-\mathrm{OH}$ group which is in consistence with the experimental results.

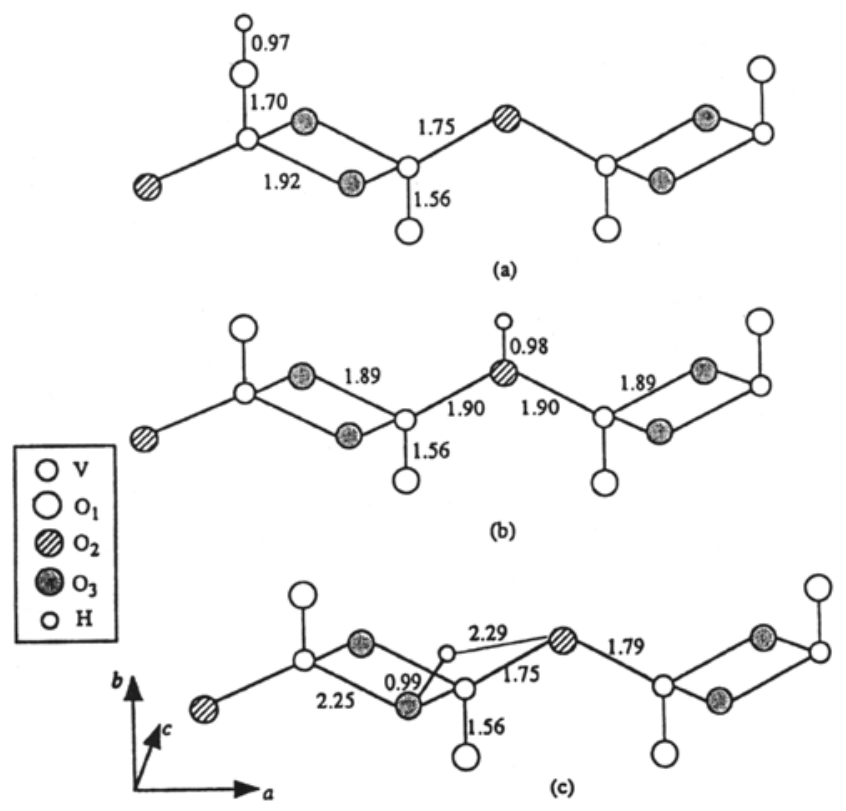

Figure 7. Fully optimized geometries of hydrogen adsorption at a. singly-coordinated oxygen, b. di-coordinated oxygen, and c. tri-coordinated oxygen sites on $\mathrm{V}_{2} \mathrm{O}_{5}(010)$.
We investigated the $\mathrm{NH}_{3}$ adsorption on the Lewis sites with different coverages, and the stability under high coverage is weaker than that under low coverage due to the steric repulsion derived from the coadsorbed $\mathbf{N H}_{3}$ molecules. In all the cases, hydrogen bonding between the $\mathrm{N}-\mathrm{H}$ and vanadyl oxygen contributes to the binding very significantly.

\section{3f Mechanism of selective catalytic reduction of NO} by $\mathrm{NH}_{3}$ : In our recent study, periodic DFT calculations were carried out to investigate the mechanism of selective catalytic reduction (SCR) of $\mathrm{NO}$ by $\mathrm{NH}_{3}$ in the presence of gaseous oxygen (Yin et al 1999d). The interaction of gaseous NO molecule on $\mathrm{V}_{2} \mathrm{O}_{5}$ surface was investigated and the results showed that the adsorptions on the three types of lattice oxygens were energetically not favourable, since both the interacting $\mathrm{N}$ and $\mathrm{O}$ atoms possess positive charge and therefore they repel each other. This therefore suggested that the SCR reaction perhaps occurs by the interaction of the gaseous NO molecule with the adsorbed $\mathrm{NH}_{4}^{+}$species. Theoretical calculations confirmed that gaseous NO indeed reacts with the adsorbed $\mathrm{NH}_{4}^{+}$to form an intermediate together with the formation energy of $-28.2 \mathrm{kcal} / \mathrm{mol}$. Furthermore, the geometry and energy of this intermediate predicted a tendency for its
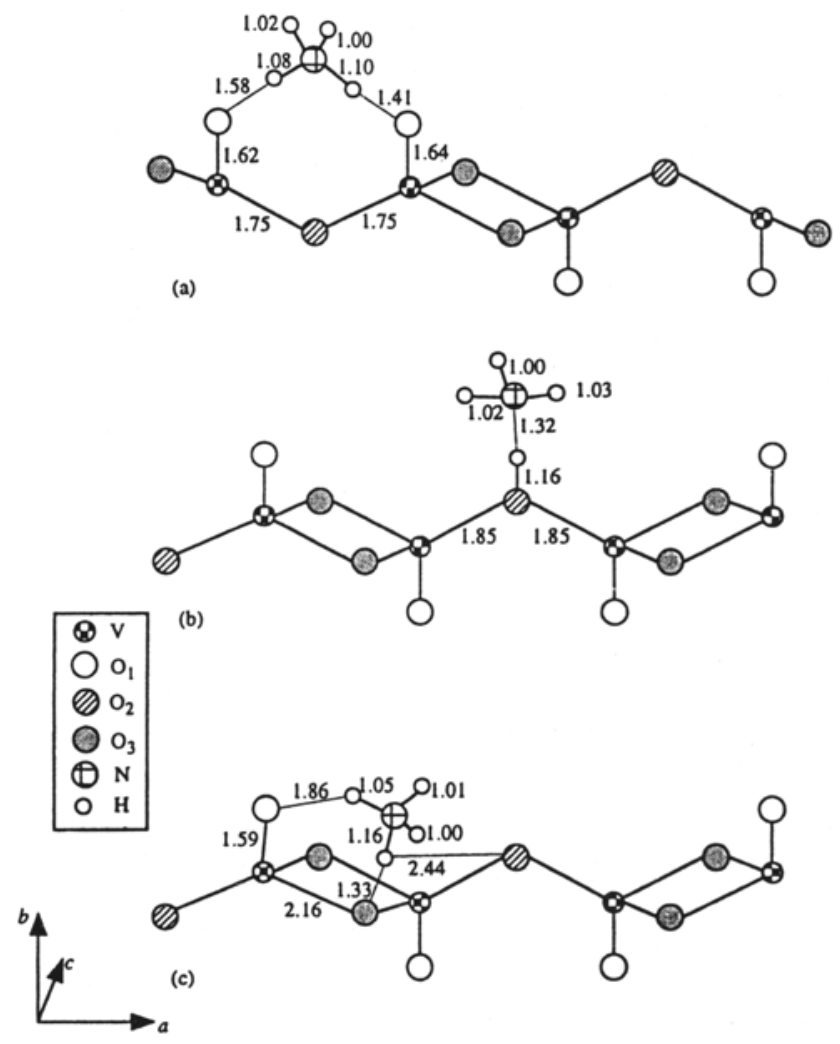

Figure 8. The geometries of ammonia adsorption at the hydroxyl species consisting of a. singly-coordinated oxygen, b. di-coordinated oxygen, and c. tri-coordinated oxygen sites on $\mathrm{V}_{2} \mathrm{O}_{5}(010)$. Bond lengths are given in $\AA$. 


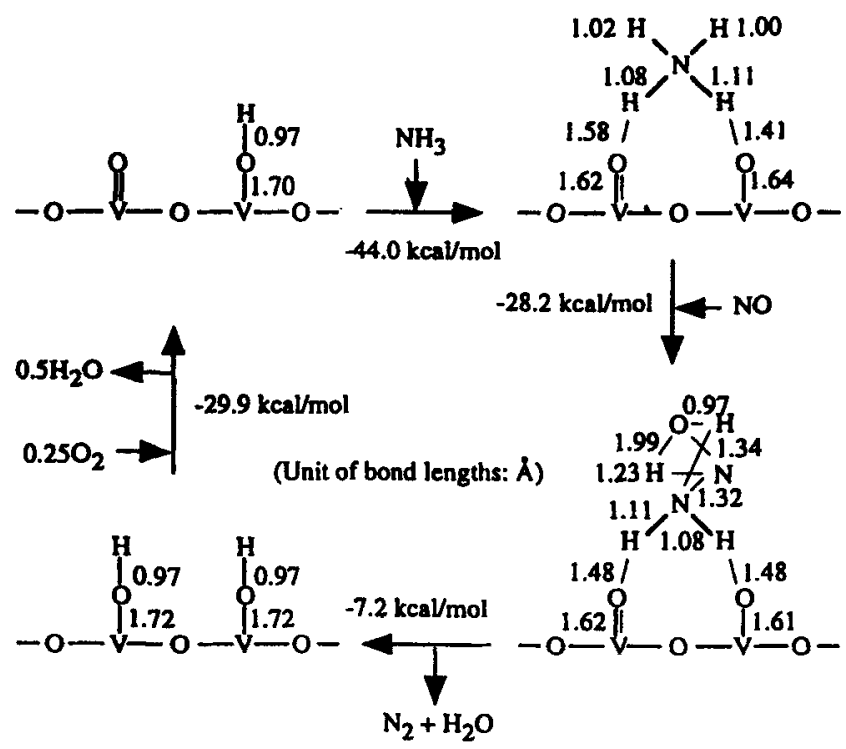

Figure 9. Mechanism of the selective catalytic reduction of NO molecule by ammonia over $\mathrm{V}_{2} \mathrm{O}_{5}(010)$ surface. The values represent interatomic distances $(\AA)$.

decomposition to form $\mathrm{N}_{2}, \mathrm{H}_{2} \mathrm{O}$, and two hydroxyl species.

We also investigated the possibility regarding oxidation of the newly formed $\mathrm{V}-\mathrm{O}_{1} \mathrm{H}$ species to $\mathrm{V}=\mathrm{O}$ group in the presence of gaseous oxygen. The corresponding enthalpy was calculated to be $-29.9 \mathrm{kcal} / \mathrm{mol}$ which is energetically favourable for carrying out the catalytic process. It was confirmed that the catalytic process of the SCR reaction follows Eley-Rideal-type mechanism, owing to the interaction of the formed $\mathrm{NH}_{4}^{+}$species with gaseous NO molecule (figure 9).

Thus, all the above results prove that the periodic firstprinciples DFT methodology, which gets rid of the artifacts of cluster approach, is more reliable for investigation of the geometric, electronic and catalytic properties of transition metal oxide catalysts.

\section{Conclusions}

In this review we have discussed our contribution in the catalyst design, and in the investigation of catalytic processes on the solid surfaces. However, we have only highlighted the outline of our studies in the area of catalysis embodying the usefulness of integrated computational chemistry techniques to solve many problems in this area, as well as to understand the mechanism of the reactions at atomic and electronic levels. We have applied these techniques to a variety of other fields as well such as, semiconductor, tribology, electronic devices, etc. Thus, we can state that with the advent of powerful computers and softwares, computational chemistry has established its role for catalysts design as well as provide plausible explanations for the critical situations where experimental has its limitations.

\section{References}

Becke A D 1988 J. Chem. Phys. 882547

Beran S 1990 Theoretical aspects of heterogeneous catalysis (ed.) J B Moffat (New York: van Nostrand Reinhold) p. 160

Broclawik E and Salahub D R 1994 Int. J. Quant. Chem. 52 1017

Broclawik E 1995 Modern density functional theory: A tool for chemistry (eds) J M Seminario and P Politzer (Amsterdam: Elsevier) p. 349

Broclawik E, Himei H, Yamadaya M, Kubo M, Miyamoto A and Vetrivel R $1995 \mathrm{~J}$. Chem. Phys. 1032102

Broclawik E, Yamauchi R, Endou A, Kubo M and Miyamoto A 1996 J. Chem. Phys. 1044098

Broclawik E, Haber J, Endou A, Stirling A, Yamauchi R, Kubo $\mathrm{M}$ and Miyamoto A $1997 \mathrm{~J}$. Mol. Catal. A119 35

Delley B 1990 J. Chem. Phys. 92508

Demontis P, Suffritti G B, Quarteri S, Fois E S and Gamba A 1987 Zeolites 7522

Endou A, Yamauchi R, Kubo M, Stirling A and Miyamoto A 1997 Appl. Surf. Sci. 119318

Ewald P P 1921 Ann. Phys. (Leipzig) 64253

Himei H, Yamadaya M, Kubo M, Vetrivel R, Broclawik E and Miyamoto A 1995 J. Phys. Chem. 9912461

Kanougi T, Furukawa K, Yamadaya M, Oumi Y, Kubo M, Stirling A, Fahmi A and Miyamoto A 1997 Appl. Surf. Sci. 119103

Kawamura K 1989 Introduction to molecular simulations (eds) I Okada and E Osawa (Tokyo: Kaibun-do) chs 6 and 7

Kikuchi E and Yogo K 1994 Catal. Today 2273

Kohn W and Sham L J 1965 Phys. Rev. A140 1133

Kummer J T 1986 J. Phys. Chem. 904747

Lee C, Yang W and Parr R G 1988 Phys. Rev. B37 785

Miura R, Yamano H, Yamauchi R, Katagiri M, Kubo M, Vetrivel R and Miyamoto A 1995 Catal. Today 23409

Miyamoto A and Kubo M 1993 Sekiyu Gakkashi 36282

Miyamoto A, Himei H, Oka Y, Maruya E, Katagiri M, Vetrivel $R$ and Kubo M 1994 Catal. Today 2287

Moruzzi V L, Janak J F and Williams A R 1978 Calculated electronic properties of metals (New York: Pergamon)

Nicholas J B, Trouw F R, Mertz J E, Iton L E and Hopfinger A J 1993 J. Phys. Chem. 974149

Oumi Y, Matsuba K, Kubo M, Inui T and Miyamoto A 1995 Microporous Mater. 453

Oumi Y, Yamadaya M, Kanougi T, Kubo M, Stirling A, Vetrivel R, Broclawik E and Miyamoto A 1997 Catal. Lett. 4521

Perdew J P and Zunger A 1981 Phys. Rev. B23 5048

Santikary P, Yashonath S and Ananthakrishna G 1992 J. Phys. Chem. 9610469

Sauer J 1989 Chem. Rev. 89199

Shelef M and Graham G W 1994 Catal. Rev.-Sci. Eng. 36433

Stirling, A, Gunji 1, Endou A, Oumi Y, Kubo $M$ and Miyamoto A 1996 Proc. Int. Symp. Mater. Chem. Tsukuba, Japan p. 461 
Tabata T, Kokitsu M and Okada O 1994 Catal. Lett. 25393

Teter M P, Payne M C and Allan D C 1989 Phys. Rev. B40 12255

Titiloye J O, Parker S C, Stone F S and Catlow C R A 1991 J. Phys. Chem. 954038

Verlet L 1967 Phys. Rev. 15998

Vetrivel R, Kubo M, Himei H, Maruya E, Katagiri M, Broclawik E and Miyamoto A 1995 Stud. Surf. Sci. Catal. 92 233

von Barth U and Hedin L 1972 J. Phys. Chem. 51629

Vosko S H, Wilk L and Nusair M 1980 Can. J. Phys. 58 1200

Yamadaya M, Himei H, Kanougi T, Oumi Y, Kubo M, Stirling A, Vetrivel R, Broclawik E and Miyamoto A 1997 Stud. Surf. Sci. Catal. 1051485
Yin X, Miura R, Endou A, Gunji I, Yamauchi R, Kubo M, Stirling A, Fahmi A and Miyamoto A 1997 Appl. Surf. Sci. 119199

Yin X, Fahmi A, Endou A, Miura R, Gunji I, Yamauchi R, Kubo M, Chatterjee A and Miyamoto A 1998 Appl. Surf. Sci. 130539

Yin X, Han H, Endou A, Kubo M, Teraishi K, Chatterjee A and Miyamoto A 1999a J. Phys. Chem. B103 1263

Yin X, Fahmi A, Han H, Endou A, Salai Cheettu Ammal S, Kubo M, Teraishi K and Miyamoto A 1999b J. Phys. Chem. B103 3218

Yin X, Han H, Gunji I, Endou A, Salai Cheettu Ammal S, Kubo $M$ and Miyamoto A 1999c J. Phys. Chem. B103 4701

Yin X, Han H, Gunji I, Endou A, Salai Cheettu Ammal S, Kubo $M$ and Miyamoto A 1999d (under preparation) 